\title{
Estatuto de las Fuerzas Armadas Revolucionarias de Colombia, Ejército del Pueblo (1978-2007)
}

Fuerzas Armadas Revolucionarias de Colombia, Ejército del Pueblo (FARC-EP)

La Segunda Conferencia Nacional, constitutiva de las FARC, plasmó en un Reglamento Interno las normas que las rigen, su régimen organizativo y disciplinario.

La Tercera Conferencia Nacional de las FARC hizo al reglamento algunas enmiendas y le introdujo nuevos conceptos político-militares.

La Sexta Conferencia Nacional de Guerrilleros reglamentó la vida interna de las FARC en tres documentos fundamentales a saber:
A. EL PRESENTE ESTATUTO.
B. EL REGLAMENTO DE REGIMEN DISCIPLINARIO.
C. LAS NORMAS INTERNAS DE COMANDO.

La Séptima Conferencia Nacional reforma y amplía los documentos anteriores de conformidad con el paso que da el movimiento al adquirir el carácter de FUERZAS ARMADAS REVOLUCIONARIAS DE COLOMBIA - EJERCITO DEL PUEBLO (FARC-EP).

El Estatuto formula en esencia, los fundamentos ideológicos de las FARC-EP, define su estructura orgánica, el régimen de comando, los deberes y los derechos de los Combatientes y otros principios básicos de la organización revolucionaria.

El Reglamento de Régimen Disciplinario trata cuestiones esenciales de orden militar. 
Las Normas Internas de Comando tratan lo habitual en el ejercicio diario de la diversas unidades de las FARC-EP, incluidas comisiones, misiones y Unidades Tácticas de Combate (UTC).

La Octava Conferencia de las FARC-EP introduce y actualiza disposiciones estatutarias, reglamentarias y normativas, al tiempo que estatuye los Bloques de Frentes, los Comandos Conjuntos y el Comando General que dirigirá la ofensiva.

La Novena Conferencia de las FARC-EP ratifica los presentes documentos, introduce y actualiza algunas disposiciones reglamentarias y normativas y hace un llamado a la aplicación en su espíritu y su letra.

\section{CAPITULO I}

\section{ARTICULO $1^{\circ}$}

Las Fuerzas Armadas Revolucionarias de Colombia, Ejército del Pueblo, como la expresión más elevada de la lucha revolucionaria por la liberación nacional, son un movimiento político-militar que desarrolla su acción ideológica, política, organizativa, propagandística y armada de guerrillas, conforme a la táctica de combinación de todas las formas de lucha de masas por el poder para el pueblo.

\section{ARTICULO $2^{\circ}$}

Las FARC-EP, son ante todo una organización revolucionaria. Cada Escuadra o unidad básica, es al mismo tiempo célula política.

Los comandantes son miembros de las células, pero no pueden ocupar cargos de dirección celular.

El mando garantiza su reunión y da respuesta a las inquietudes planteadas por la célula política.

Las FARC-EP aplican a la realidad colombiana los principios fundamentales del marxismo-leninismo y se rigen por su Plan Estratégico y Programa Revolucionario, las conclusiones de sus Conferencias 
Nacionales, los Plenos de su Estado Mayor Central y su Reglamento Interno; se inspiran en el pensamiento revolucionario del Libertador Simón Bolívar del antiimperialismo, la unidad latinoamericana, de la igualdad y del bienestar del pueblo. También propugnan por la creación de un auténtico Ejército Bolivariano.

Las FARC-EP están a disposición y bajo el mando directo del Estado Mayor Central.

\section{CAPITULO II}

\section{ARTICULO $3^{\circ}$}

La estructura de las FARC-EP corresponde al siguiente orden:

A. ESCUADRA: Es la unidad básica y consta de doce (12) hombres, incluidos sus mandos.

B. GUERRILLA: Consta de dos (2) Escuadras, más sus mandos (26 hombres).

C. COMPAÑIA: Consta de dos (2) Guerrillas, más sus mandos (54 hombres).

D. COLUMNA: Consta de dos (2) Compañías o más, más sus mandos (110 hombres).

E. FRENTE: Consta de más de una Columna.

F. Los Estados Mayores de Frente son designados por el Estado Mayor Central. En la columna, Compañía o Guerrilla donde no exista Estado Mayor de Frente, sus respectivos comandos de dirección están formados por los comandantes que designe el Estado Mayor Central.

Donde exista Estado Mayor de Frente, los comandos de Columna, Compañía o Guerrilla, son designados por éste, así como los comandantes y reemplazantes de Escuadra, con los comandantes que hagan 
parte del cuerpo de mando, o con compañeros promovidos al mando y aprobados por el Estado Mayor Central.

G. BLOQUE DE FRENTES: Consta de cinco (5) o más Frentes. Es una estructura militar que bajo la dirección del Estado Mayor Central de las FARC-EP o su Secretariado, coordina y unifica la actividad de los Frentes en una zona específica del país en desarrollo del Plan Estratégico.

H. Los Estados Mayores de Bloque son designados por el Estado Mayor Central o su Secretariado. Coordinan en las áreas de los respectivos Bloques, las campañas militares y todos los planes emanados de las Conferencias, de los Plenos del Estado Mayor Central y del Secretariado. Centralizan, en coordinación con el Estado Mayor Central, las relaciones políticas a nivel de área de Bloque y ejecutan y controlan el desarrollo de los planes particulares de los Frentes.

Los permisos que impliquen salida a la ciudad de mandos medios, de miembros de Estado Mayor de Frente y de Estado Mayor de Bloque a misiones o tratamiento médico, etc., serán previamente consultados por la dirección del Bloque al Secretariado quien finalmente resuelve sobre ellos. Igual procedimiento se aplicará para definir casos de ajusticiamiento. Los reajustes de los Estados Mayores de los Frentes son facultad exclusiva del Estado Mayor Central o su Secretariado. Los Estados Mayores de los Bloques, previa consulta a los organismos superiores mencionados, laborarán un régimen particular para el trabajo urbano en sus respectivas áreas.

I. COMANDO CONJUNTO: Cuando no estén dadas las condiciones para la creación de un Bloque de Frentes funcionará un Comando Conjunto que unificará y coordinará la actividad de los Frentes en un área. Los Comandos Conjuntos tendrán un coordinador y dependen directamente del Estado Mayor Central o su Secretariado. 
J. COMANDO GENERAL: Logradas las metas de la segunda fase del Plan entrará en funcionamiento el Comando General que dirigirá la ofensiva.

K. El Estado Mayor Central es el organismo superior de dirección y mando de las FARC-EP, en todos sus escalones. Sus acuerdos, órdenes y determinaciones obligan a todo el movimiento y a todos sus integrantes.

\section{CAPITULO III REGIMEN DE COMANDO}

\section{ARTICULO $4^{\circ}$}

La estructura jerárquica de las FARC-EP, es como sigue:

a. REEMPLAZANTE DE ESCUADRA.

b. COMANDANTE DE ESCUADRA (12 h.).

c. REEMPLAZANTE DE GUERRILLA.

d. COMANDANTE DE GUERRILLA (26 h.).

e. REEMPLAZANTE DE COMPAÑIA.

f. COMANDANTE DE COMPAÑIA (54 h.).

g. REEMPLAZANTE DE COLUMNA.

h. COMANDANTE DE COLUMNA (110 h.).

i. REEMPLAZANTE DE FRENTE.

j. COMANDANTE DE FRENTE (más de una Columna.).

k. REEMPLAZANTE DE BLOQUE.

I. COMANDANTE DE BLOQUE (5 o más Frentes.).

m. REEMPLAZANTE DE ESTADO MAYOR CENTRAL. 


\section{n. COMANDANTE DE ESTADO MAYOR CENTRAL.}

ñ. COMANDO GENERAL: Está integrado por el Secretariado y los jefes de los Bloques para proyectar y dirigir la ofensiva final.

o. Son organismos colegiados de dirección y mando el Estado Mayor Central, el Comando General, los Estados Mayores de Bloque y de Frente, y los Comandos de Columna, Compañía, Guerrilla y Escuadra. Las anteriores instancias de dirección se rigen por el principio de la dirección colectiva.

p. Los cuadros estarán sujetos a reubicación o traslado de acuerdo al desarrollo del plan.

\section{ARTICULO $5^{\circ}$}

Para cada responsabilidad en el mando, se crea el correspondiente distintivo cuyo uso controla el Estado Mayor Central.

\section{ARTICULO $6^{\circ}$}

Los requisitos para ser comandante son:

a. Capacidad militar y don de mando.

b. Tener dos años en filas, desempeñando las tareas señaladas y haber observado buena conducta.

c. Haber mostrado interés por elevar el nivel ideológico de los combatientes.

d. Haber cumplido y defendido las determinaciones de los organismos superiores de las FARC-EP y haberse destacado en el cumplimiento de las normas disciplinarias.

e. Ser militante activo de la organización política.

f. Saber orientarse en situaciones difíciles, ser sereno, valeroso, reflexivo, respetuoso de los demás y modesto. 
g. Tener temple revolucionario y elevada moral y estar dotado de honestidad ejemplar.

h. Haber tenido y tener profundo respeto por los intereses de la población civil, portarse correctamente con ellas y ganarse su confianza.

i. Saber leer y escribir.

\section{CAPITULO IV \\ DE LOS DEBERES Y LOS DERECHOS}

\section{ARTICULO $7^{\circ}$}

Los deberes de los combatientes son:

a. Ser honesto y veraz con el movimiento, abnegado en la lucha y modesto.

b. Mantener siempre en alto el prestigio de la organización política revolucionaria y de las FARC-EP y hacer que los demás hagan lo mismo.

c. Cumplir estrictamente las determinaciones y órdenes con espíritu de iniciativa.

d. Hacer esfuerzos permanentes por superarse en los terrenos político, cultural y militar.

e. Trabajar por la unidad y la armonía, la fraternidad y la solidaridad dentrodel movimiento.

f. Mantener una actitud vigilante en defensa de la unidad del movimiento y desenmascarar oportunamente el trabajo de zapa y el espionaje del enemigo.

g. Hacer uso correcto de la crítica frente a los errores y defectos y hacer su orrespondiente autocrítica cuando le sean señalados errores o faltas. 
h. Defender los intereses y bienes del movimiento, de la organización política y de la población civil.

i. Guardar y hacer guardar los secretos y la reserva del movimiento.

j. Dar prueba de firmeza ante el enemigo en todas las circunstancias.

k. Respetar a los prisioneros de guerra en su integridad física y convicciones.

\section{ARTICULO $8^{\circ}$}

Los derechos de los combatientes son:

a. Participar en la vida de su unidad básica y en el organismo político de ella.

b. Elegir y ser elegido a puestos de representación.

c. Criticar a sus compañeros y superiores en el organismo político, en las Asambleas Generales de Guerrilleros, en los Comandos de Unidad, en los Estados Mayores de Frente, en los Estados Mayores de Bloque, en el Comando General y en las Conferencias Nacionales, por errores o faltas etc.

d. Presentar propuestas, sugerencias, iniciativas y comunicar los defectos que observe en el desarrollo de cualquier tarea al escalón correspondiente, incluso, al Estado Mayor Central. Las distintas instancias de dirección garantizarán que las notas o cartas enviadas por los combatientes en este sentido, lleguen a su destino.

e. Recibir los estímulos políticos y morales del movimiento como cargos de responsabilidad y representación, delegaciones y demás que se conquisten a base de abnegación, espíritu de sacrificio de compañerismo y lucha. 
f. Exigir su participación personal cuando se trate de tomar decisiones sobre su propia actuación y conducta, cuando no se trate de delitos ya comprobados.

g. Los deberes y los derechos en las FARC-EP son iguales para todos sus integrantes pero sin igualitarismo pequeño-burqués.

\section{CAPITULO V}

\section{ARTICULO $9^{\circ}$}

Las FARC-EP se componen de combatientes que se unen conscientemente en la lucha armada. A filas se llega por tiempo indefinido. Los combatientes de las FARC-EP son profesionales revolucionarios hasta el triunfo de la revolución y conforme a los planes nacionales y de Frente que traza el Estado Mayor Central y que son plasmación de diversas tareas en concordancia con las necesidades y posibilidades de cada Frente o unidad armada. El licenciamiento de filas lo estudia y decide el Estado Mayor Central cuando se trate de miembros de éste, de integrantes de Estado Mayor de Bloque, de Estado Mayor de Frente, de los comandantes o comandos designados por la Conferencia Nacional o por el Estado Mayor Central; y cuando se trate de integrantes de base de Frente, el licenciamiento de filas lo estudia y resuelve el Estado Mayor de Bloque, previa consulta con el Secretariado. Las instancias de mando correspondientes reubicarán y prestarán asistencia a los compañeros que resulten lisiados por la guerra.

\section{ARTICULO $10^{\circ}$}

La disciplina de las FARC-EP, es político militar y la contempla éste Estatuto, el reglamento de Régimen Disciplinario, las Normas de Comando, los Estatutos Políticos y las Resoluciones de las conferencias nacionales de las FARC-EP. 


\section{ARTICULO $11^{\circ}$}

Los cuadros dirigentes de las FARC-EP desde los Comandantes de Escuadra, responsables auxiliares, jefes de misiones, comisiones y UTC, hasta los miembros del Estado Mayor Central, asumen mayores responsabilidades y responderán ante las Conferencias Nacionales de Guerrilleros y organismos políticos superiores de la orientación política, la organización, la educación y elevación de la capacidad militar de los combatientes, así como del cumplimiento del presente Estatuto, el Reglamento de Régimen Disciplinario y las Normas Internas de Comando.

\section{ARTICULO $12^{\circ}$}

Todos los materiales aprobados por la Conferencia y el Estado Mayor Central son de obligatorio cumplimiento para el conjunto de las FARC-EP.

\section{ARTICULO $13^{\circ}$}

Las armas, parques, equipos, dotaciones, dinero, otros muebles e inmuebles tomados en acción al enemigo, o adquiridos en una u otra forma en el proceso de la lucha, con apoyo directo o indirecto del movimiento y aunque la acción realizada sea por una sola persona se considera propiedad colectiva de las FARC-EP. La apropiación de todo o parte de lo adquirido es delito de robo al movimiento.

\section{CAPITULO VI}

\section{ARTICULO $14^{\circ}$}

Las FARC-EP, en su práctica militar se rigen por planes generales del Estado Mayor Central diseñados por las Conferencias Nacionales de Guerrilleros, que obligan a su cumplimiento a misiones, comisiones, UTC, Escuadras, Guerrillas, Compañías, Columnas, Frentes, Bloque de Frentes y Estado Mayor Central. Los planes sufrirán variaciones únicamente en el sentido del incremento en cada unidad, 
cuando ésta proyecte y realice su propio plan, tomando las metas del Plan General Nacional. El Secretariado del Estado Mayor Central, está facultado para reajustar el Plan General Nacional, cuando lo considere necesario.

\section{CAPITULO VII \\ DEL REGIMEN INTERNO}

\section{ARTICULO $15^{\circ}$}

El Régimen Interno General de las FARC-EP, lleva el nombre de Normas de Comando y es igual y uniforme para todos los guerrilleros y comandantes y para los diversos escalones del movimiento. El Régimen interno General, junto con las materias: Gimnasia, Judo y defensa personal, instrucción militar de orden cerrado y abierto, constituyen la Cartilla de Instrucción de todas las unidades de las FARC-EP. Los Estados Mayores de Frente al actualizar para cada situación concreta el Régimen Interno General, elaborarán el Régimen Interno Particular de cada unidad, que deberá contemplar lo resultante de cada situación, los planes de cuartel o campamento, planes de marcha y planes de labor, cuando no se esté en orden público.

\section{CAPITULO VIII}

\section{ARTICULO $16^{\circ}$}

Los ascensos militares los otorga la Conferencia Nacional, el Estado Mayor Central o su Secretariado. Así mismo el Estado Mayor Central o su Secretariado, están facultados para suspender grados como sanción por faltas graves en función del cargo y para separar de las FARC-EP, a comandantes o miembros del Estado Mayor Central que violen los principios establecidos en el Estatuto, el Reglamento de Régimen Disciplinario y las Normas Internas de Comando. 


\section{CAPITULO IX \\ DEL HIMNO Y DEL EMBLEMA}

\section{ARTICULO $17^{\circ}$}

Las FARC-EP tienen un himno y un emblema. El himno aparece al final del presente documento. El emblema de las Fuerzas Armadas Revolucionarias de Colombia es la bandera nacional de la República con los trazos fronterizos del mapa de su territorio. En el centro de ella $\mathrm{y}$ dentro del trazo del mapa dos fusiles cruzados formando una $\mathrm{X} \mathrm{y}$ sobre el ángulo superior de ésta un libro abierto.

\section{CAPITULO X}

\section{ARTICULO $18^{\circ}$}

El presente estatuto es válido para todos los integrantes de las Fuerzas Armadas Revolucionarias de Colombia, Ejército del Pueblo, y para todos los escalones del movimiento. Su reforma corresponde a la Conferencia Nacional de Guerrilleros de las FARC-EP.

SEXTA CONFERENCIA DE LAS FARC

18 - 25 de enero de 1978

SEPTIMA CONFERENCIA DE LAS FARC-EP

04 - 14 de mayo de 1982

OCTAVA CONFERENCIA DE LAS FARC-EP

11 - 18 abril de 1993

NOVENA CONFERENCIA DE LAS FARC-EP

9 abril de 2007 